\title{
Confidence and Work Period Interests Independent Practice Nurse in Banjarmasin
}

\author{
Mohammad Basit ${ }^{1}$, Chindy Widy Antiariani ${ }^{2}$ \\ syafabasit@gmail.com ${ }^{1}$ chindy.w14@gmail.com² \\ ${ }^{12}$ Universitas Sari Mulia, Banjarmasin, Indonesia
}

\begin{abstract}
Background: Low interest independent practice nurses in Banjarmasin background of several things including confidence in terms of skills / skill, and years of service affects the level of skill and experience in the nurses'. Independent practice operating licenses is governed by the Minister of Health RI 148 in 2010 and the Nursing Act 38 of 2014 which states that nurses can legally run independent practice of nursing. In order to know the relationship of confidence and years of independent practice nurses with an interest in Banjarmasin. Analytic survey method with cross sectional approach. Banjarmasin nurse population. Purposive sampling technique amounted to 81 people. Tools of data collection questionnaires were analyzed using Spearman rank correlation test with significance level of $95 \%(\alpha=0.05)$. Results: Many respondents have confidence in both totaling 28 people (34.6\%), long working life (> 10 years) had the largest number that is numbered $42(51.9 \%)$, interest in independent practice nurse was of 48 people (59.3\%).

Conclusion: There is a significant relationship between confidence in independent practice nurses interest Banjarmasin $(\mathrm{p}=0.000)$ and no past relationship working toward independent practice nurses interest Banjarmasin $(\mathrm{p}=0.259)$.
\end{abstract}

Keywords: confidence, employment, interest in independent practice

\section{INTRODUCTION}

The nurse is one of the health professionals and integral part of the health service. Nurses have a specific body of knowledge and practice in carrying his profession has a responsibility and accountability as well as bound by legal rules governing the practice of health professionals. Judging from the amount, nurses are health workers in Indonesia that is equal to $32.8 \%$ of the total available health workers (Nursalam, 2015).

Based on data from the Health Profile In 2013, the number of nursing personnel in Indonesia as many as 288045 nurses. As a healthcare professional, nurses have the authority to practice nursing care in accordance with the standards of ethics and professional standards that apply. Of 1 million nurses in Indonesia, the majority or $80 \%$ of nurses who work in hospitals vertical educated Diploma, Diploma IV $0.5 \%$, S1 Nursing degree * $1 \%$, nurses $11 \%$, and the degree * Two 0.4\%, whereas educated nurses School Health nurse (SPK) as much as 7\%. The number of nurses in all hospitals by the Hospital Information System (SIRS 2015) as many as 668 552 people, while the number of nurses working in the health center by the Health Profile of 2015 amounted to as much as 152753 people. Nursing staff has a major contribution in achieving the 
performance of health centers and hospitals. Therefore, the quality of nurses will continue to increase professionalism on an ongoing basis (MoH RI, 2015).

Nurses who have the confidence to be willing to take risks and dare to face health problems not only in the environment where he works but also the environment of the residence and the wider environment. Nurses who work long already has extensive experience in treating patients with various health problems.

From the results of a survey conducted in hospitals Ulin Banjarmasin, note that hospitals Ulin in the period January to December 2016, have nurses PNS 406 people consisting of 173 men and 233 women, a total of 252 nurses employee non-civil consists of 96 men and 156 women nurses and admin as many as 12 people. This study aimed to analyze the relationship of confidence and years of independent practice nurses with an interest in Banjarmasin Ulin General Hospital.

\section{MATERIALS AND METHODS}

This type of research using analytic survey with cross sectional approach. The target population was all nurses in hospitals Ulin Banjarmasin. Samples portion of the population is taken using purposive sampling techniques amounted to 81 people. Data collection technique used questionnaires were analyzed using Spearman rank correlation test with significance level of $95 \%(\alpha=0.05)$.

\section{RESULTS}

1. Test Data Analysis In univariate

a. Hospital nurse Confidence Ulin Banjarmasin

Table 1 Distribution Frequency Hospital nurse Confidence Ulin Banjarmasin

\begin{tabular}{ccc}
\hline $\begin{array}{c}\text { Confidence } \\
\text { Nurses }\end{array}$ & F & $\%$ \\
\hline Less & 26 & 32.1 \\
\hline Enough & 27 & 33.3 \\
\hline Well & 28 & 34.6 \\
\hline Amount & 81 & 100 \\
\hline
\end{tabular}

Table 1 shows that good confidence totaling 28 people (34.6\%). 
b. Hospital Nurses Work Period Ulin Banjarmasin

Table 2 Frequency Distribution of Hospital Nurses Work Period Ulin Banjarmasin

\begin{tabular}{ccc}
\hline Years of service & $\mathrm{F}$ & $\%$ \\
\hline Medium (5-10 Years) & 39 & 48.1 \\
\hline Old (> 10 years) & 42 & 51.9 \\
\hline amount & 81 & 100 \\
\hline
\end{tabular}

Table 2 shows that long working life (> 10 years) had the largest number that is numbered $42(51.9 \%)$.

c. Hospital Independent Practice Nurse interest Ulin Banjarmasin

Table 3 Distribution of Interest in Independent Practice Nurse Hospital Ulin Banjarmasin

\begin{tabular}{ccc}
\hline $\begin{array}{c}\text { Interests Independent } \\
\text { Practice Nurse }\end{array}$ & $\mathrm{F}$ & $\%$ \\
\hline Weak interest & 9 & 11.1 \\
\hline Average interest & 48 & 59.3 \\
\hline Strong interest & 24 & 29.6 \\
\hline amount & 81 & 100 \\
\hline
\end{tabular}

Table 3 shows that minat independent practice nurses being of 48 people $(59.3 \%)$.

\section{Test Data Analysis In Bivariat}

a. Confidence relationship with Nurse Hospital Independent Practice Interests in Ulin Banjarmasin

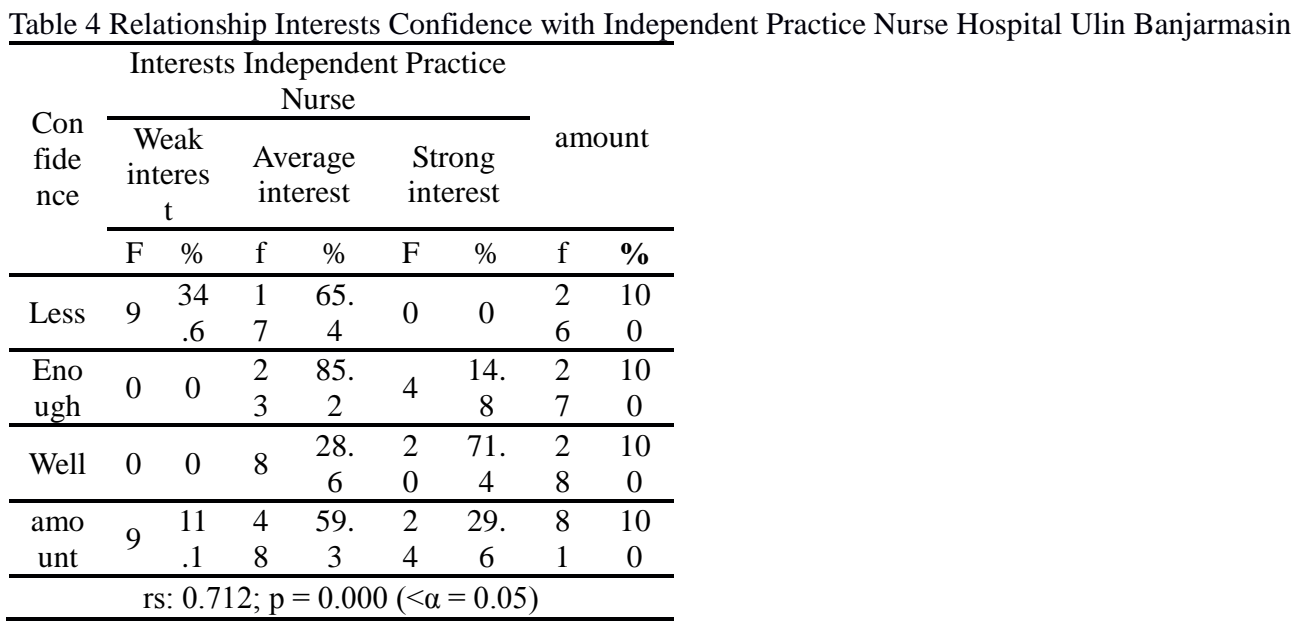

Table 4 shows that nurses who have the confidence lacking most of the interest in independent practice nurses were as many as 17 people $(65.4 \%)$, nurses have sufficient confidence to the interests sebaagian large independent practice nurses were as many as 23 people $(85.2 \%)$, nurses who have good confidence largely independent practice nurses with a strong interest in as many as 20 people (71.4\%). 
The results of the analysis with the Spearman rank correlation test showed that the value of rs: $0.712 ; \mathrm{p}=0.000<\alpha=0.05$ or it can be said that there is a significant relationship between confidence against the interest of independent practice nurses Hospital Ulin Banjarmasin,

The correlation coefficient (rs) (0.712) positive value means the value of a strong correlation between the two variables have a perfect linear relationship (straight line) is positive. This perfect correlation has meaning if the value of the confidence is good, theninterest in independent practice nurses also strong.

b. Work Period Interests relationship with Independent Practice Nurse Hospital Ulin Banjarmasin

Work Period Table 5 Relationship with Independent Practice Nurse Interests Hospital Ulin Banjarmasin

\begin{tabular}{|c|c|c|c|c|c|c|c|c|}
\hline \multirow{3}{*}{ Years of service } & \multicolumn{6}{|c|}{ Interests Independent Practice Nurse } & \multirow{2}{*}{\multicolumn{2}{|c|}{ amount }} \\
\hline & \multicolumn{2}{|c|}{$\begin{array}{c}\text { Weak } \\
\text { interest }\end{array}$} & \multicolumn{2}{|c|}{$\begin{array}{c}\text { Average } \\
\text { interest }\end{array}$} & \multicolumn{2}{|c|}{ Strong interest } & & \\
\hline & $\mathrm{f}$ & $\%$ & $\mathrm{f}$ & $\%$ & $\mathrm{f}$ & $\%$ & $\mathrm{f}$ & $\%$ \\
\hline $\begin{array}{c}\text { Medium (5-10 } \\
\text { years) }\end{array}$ & 5 & 12.8 & 19 & 48.7 & 15 & 38.5 & 39 & 100 \\
\hline Old $(>10$ years $)$ & 4 & 9.5 & 29 & 69 & 9 & 21.4 & 42 & 100 \\
\hline amount & 9 & 11.1 & 48 & 59.3 & 24 & 29.6 & 81 & 100 \\
\hline \multicolumn{9}{|c|}{$\mathrm{p}=0.259(\geq \alpha=0.05)$} \\
\hline
\end{tabular}

The results of the 81 nurses in mind that most of the nurses who have tenure medium (5-10 years) with interest in independent practice nurses were as many as 19 people $(48.7 \%)$ and nurses who have a long working life (> 10 years) with interest independent practice nurses were as many as 29 people $(69.0 \%)$.

The results of the analysis with the Spearman rank correlation test showed that the value of $p=0.259 \geq \alpha=0.05$ or it can be said that there is no significant relationship between tenure on the interest of independent practice nurses Hospital Ulin Banjarmasin,

\section{DISCUSSION}

\section{Confidence}

Results of research on confidence in mind that most nurses have good self confidence totaling 28 people (34.6\%), while lacking confidencetotaling 26 people (32.1\%). This is due 
to come on questionnaires the nurses who have good self confidence because they trust and confidence with competence and capability themselves without recognition of others were able to be successful.

Less confidence in this study due to the nurses are not able to control themselves and emotions. They are afraid of starting a job and selalun be the last person to come forward thing is based on the results of questionnaires, in addition to government regulation there is no age limit for a nurse in opening an independent practice. The study says that most of the respondents who had been independent practice aged $>40$ years this is due to the age of entering the retirement age so that the nurses be better prepared for retirement by opening an independent practice.

The confidence is essential for someone who wants to progress, achievement and better developed. A nurse who has the confidence is lacking, unable to develop the skills they have. This can result in less work experience and the lack of development of science better. It is different from the high-confident people. Nurses who have the confidence to be willing to take risks and dare to face health problems not only in the environment where he works but also the environment of the residence and the wider environment (Nursalam, 2015).

Research conducted by Indra (2010), showed that nurses in Indramayu Power mostly have good confidence in the work because the confidence is good then the work produced will be good too. Good confidence into the capital for a nurse to deal with patients because of the confidence that both patients have high confidence to recover as cared for by a nurse who is able to control himself and be able to increase the confidence of patients to be treated by the nurse properly.

According to the assumptions of researchers confidence nurses are high can result from several factors such as the science of high coupled with skill or high skill, in addition to the influence of support from parents, relatives, co-workers and leaders were able to increase the confidence of nurses in the work, while the nurses were lacking confidence caused by 
factors that are less productive nurses age (> 35 years) and government regulation in independent practice permit requirements which, according to the nurses too complicated.

2. Years of service

Results of research on tenure is known that most nurses have long working life (> 10 years) had the largest number that is numbered 42 (51.9\%), while the working lives being 510 years) amounted to $39(48.1 \%)$. Future work is the determination of a person's level of experience in the work. Nurses who worked already more than 10 years, in contrast with the experience of the nurse who had worked less than 10 years. Nurses who work long already has extensive experience in treating patients with various health problems. This can be a nurse as knowledge and work experience that can be applied and implemented while serving the community.

Results of research by Mustain, (2013) note that most of the nurses in the hospital is that senior nurses (working in a period of more than 10 years). This is because in addition to experience in facing and perform maintenance on the patient, it also can be used as a way to reduce mortality in patients as a nurse who has long worked to know the things that can be done as first aid to prevent complications in patients.

Through a long struggle throughout the Indonesian nurses who are members of a container that is PPNI convey that aspiration to protect the public and nurses themselves from the presumption of illegal practices to the government and parliament, with the passing of Law of Nursing, nurses who usually has conducted independent practice is legal to record the nurse fulfill and complete the licensing requirements and established nameplate as a form of notification because with no nameplate that has been deemed illegal practice nurse (PPNI, AIPNI, AIPDiKI, 2012).

Based on the results of the questionnaire is known that most of the nurses who have independent practice has been working at the hospital and served for more than 10 years because the older nurses work, the more experience and knowledge about the world of health 
obtained, it is also in accordance with pernytaan PPNI, AIPNI, AIPDiKI (2012) and in accordance with the Act of nursing that the requirement to have the permit independent practice must obtain a letter of recommendation from the organization of the nursing profession, which means nurses with tenure of more than 10 that have long followed the activity and easier to get the recommendation of practice license,

According to the assumptions of researchers working lives of the nurses play an important role in the quality of work given to the patient, the longer a nurse working the more wise in making decisions and the higher the patient's sense of trust management and the performance of nurses.

3. Interests Independent Practice

Results of research on interest in independent practice is known that most nurses have minat independent practice nurses being of 48 people (59.3\%), while mIndependent practice nurses weak inatamounted to $9(11.1 \%)$. Based on the results of questionnaires the nurses who have interests that are independent practice because they have extensive knowledge of the health world because those closest to them adalh nurses who have independent practices so that they have easy access to open independent practices. While the nurses who have interest in practice impaired by a lack of nurses learn to do new things associated with the disease, their environment many nurses who practiced and they were not enough experiences a medical equipment for independent practice.

The nurse is one of the health professionals and integral part of the health service. Nurses have a specific body of knowledge and practice in carrying his profession has a responsibility and accountability as well as bound by legal rules governing the practice of health professionals. Judging from the amount, nurses are health workers in Indonesia that is equal to $32.8 \%$ of the total available health workers (Nursalam, 2015).

The research result Fedwaro (2012), found that of 72 nurses, $60 \%$ of nurses have interest in independent practice who are which means that the interest is not too strong nor 
too weak, the majority of nurses say that the interest that is being caused by a number of considerations, namely salaries are insufficient and limited time availability.

Interest in independent practice is also influenced by several factors such as the salary is sufficient for his life, time constraints with the family for most of the nurses said that after work is a time of rest and gather with family, the relatively high cost as initial capital for the opening practice, work permits and permit independent practice with the old process, the need for promotion and trust society about the quality of nurse's performance because it will affect the accreditation from the independent practice nurses. The higher and better value places the practice nurse accreditation eat the higher and better the people's confidence in security, quality and quantity of services and increasingly the rise in public satisfaction,

4. Confidence towards Interests Relations Independent Practice Nurse Hospital Ulin Banjarmasin

The results of the analysis with the Spearman rank correlation test showed that the value of $p=0.000<\alpha=0.05$ or it can be said that there is a significant relationship between confidence in independent practice nurses interest Hospital Ulin Banjarmasin. Nurses who have a high confidence in the ability and what he has is very easy to gain the trust of society when opening an independent practice. Nurses who have a high confidence can be seen from the way the nurses providing services and strengthening its attitude while doing anything to the society so that people are confident to recover. A positive attitude in the act are sure of yourself and the environment or situation.

Based on the results of the questionnaire, most nurses give up and rely on others, often negative thinking and looking at things from a variety of things and make decisions without careful consideration and are not optimistic and do not believe that is able to repair itself and the work environment.

Terms that have been ratified by the Government in the Law of Nursing about permits independent practice such as a nurse taking care of and required to have a registration letter 
(STR), taking care permit the practice nurse (SIPP) at the district health office / town domicile nurse, have a diploma of education DIII of nursing and nursing S1 + professional nurses, have a letter of recommendation from a professional organization of nurses, a letter of revelation had a practice or a letter from the head of the HCF.

Correlation coefficient (rs) (0.712) positive value means the value of a strong correlation between the two variables have a perfect linear relationship (straight line) is positive. This perfect correlation has meaning if the value of the confidence is good, then the interest in independent practice nurses are also strong.

Each individual experiencing various problems of events, such as meeting new people and so forth. The reaction of the individual against a person or an event very influential way of thinking. Individuals who self-confidence is weak tend to look at things from the negative side, but individuals who are always equipped with a positive outlook either to others or themselves will have self-esteem and high self belief.

Research conducted by Indra (2010), showed that there is a relationship of confidence against the interest of independent practice nurses $(\mathrm{p}=0.002 ; \alpha=0.05)$. Beliefs, attitudes, feelings and aspirations of the individual himself appropriately and realistically possible to have a healthy personality. But otherwise if inappropriate and unrealistic likely to cause personal problems. This affects the confidence of the developmental tasks of nurses in shaping identity. Failure at this stage would cause confusion of roles and tasks in the development of the next stage.

The confidence is not there at birth but is the result of interaction with others, especially those closest, but it needs the support facilities in independent practice as infrastructure and permission practices are things that become another obstacle for a nurse in the open desire independent practice.

5. Relationships Work Period to the Independent Practice Nurse Interests Hospital Ulin Banjarmasin 
The results of the analysis with the Spearman rank correlation test showed that the $\mathrm{p}=$ $0.259 \geq \alpha=0.05$ or it can be said that there is no significant relationship between tenure on the interest of independent practice nurses Hospital Ulin Banjarmasin. The tenure of the nurse determine the knowledge and insight in handling various cases of the disease. The longer the nurses work, the more experience gained in dealing with various cases. Therefore, when the nurse opened the independent practice will be easier to deal with health problems complained by patients.

In humans there is a need-kebutuan which in turn form the objectives to be achieved and fulfilled. To achieve these goals, people motivated to do an activity called work. But not all activities can be said to work because jobs are activities planned and scheduled, so the work requires planning and specific objectives and can not be run by a person, he is performing not only because deploy a fun activity but by the will and kesungguh-real to reach a specific purpose (Anoraga, 2014).

Generally, in a day a person is working for 6-8 hours and the remaining 14-18 hours for rest or gather with family and hanging out with people. The addition of working hours can decrease worker efficiency, reduce productivity, the onset of fatigue and can lead to disease and accidents (Anoraga, 2014).

Research conducted by Indra (2010), showed that there was no relationship work period a nurse with an interest in independent practice nurses $(p=1.000 ; \alpha=0.05)$. Nurses working period before opening practice of self-employment is able to provide benchmark quality of the nursing work in serving the community. Work to be independent and work alone facing different problems when a nurse working in an agency or hospital earlier that are working as a team or an authorized supervisor. When working independently, nurses must be able to cope with the problem alone and the length of employment of nurses on previous work can be used as a comparison for example to reduce and improve the quality of work, 


\section{ACKNOWLEDGEMENT}

Researchers would like to thank profusely to Hospital Ulin Banjarmasin give permission to place this study, and the nurses who are willing to be the respondent.

\section{REFERENCES}

[1] Indra. R. Evaluation of Independent Nursing Practice Nursing Based Rule in Indramayu. Health Journal: Vol. 12 Issue 2. [Internet] available on http //: www.healthy.co.id. [Accessed: February 8, 2016].(2010).

[2] MoH RI. Basic Health Research, Infodantin: Independent Practice Nurse. Jakarta: Ministry of Health of the Republic of Indonesia.(2015).

[3] _. National Development: Towards Healthy Indonesia 2025 Jakarta: Ministry of Health of the Republic of Indonesia.(2015).

[4] Mustain. The role of the organization in the independent practice of nursing supervision in Kudus, Central Java. Health Journal Issue 2. Jakarta: Faculty of Medicine. [Internet] available on http //: www.healthy.co.id. [Accessed: February 8, 2016].(2013).

[5] Nursalam. Education in Nursing. Jakarta: Salemba. Medika.(2013).

[6] Nursing Management and Application. Jakarta: Publisher Salemba. Medika.

[7] PPNI, AIPNI, AIPDiKI. Nursing Education Standards Indonesia. Education Expert Panel Meeting Keperawan. Jakarta: Indonesian National Nurses Association (PPNI).(2012).

[8] Sari. Promotion Potential and Feasibility of Nursing. Jakarta: World Library.(2015) 